\title{
Endobronchial Ultrasound (EBUS) for Local Drug Application: Future Methodology
}

\author{
Paul Zarogoulidis ${ }^{\bowtie}$, Mina Gaga ${ }^{2}$, Wolfgang Hohenforst-Schmidt ${ }^{3}$, Haidong Huang ${ }^{4}$, Chong Bai ${ }^{4}$, Kaid \\ Darwiche ${ }^{5}$, Georgia Trakada ${ }^{6}$, Xrysa Sardeli7 ${ }^{7}$ Aggeliki Rapti ${ }^{8}$, Lutz Freitag ${ }^{5}$ \\ 1. Pulmonary Oncology Unit, "G. Papanikolaou" General Hospital, Aristotle University of Thessaloniki, Thessaloniki, Greece \\ 2. 7th Respiratory Medicine Department and Asthma Center, Athens Chest Hospital 'Sotiria', Athens, Greece. \\ 3. Medical Clinic I, "Fuerth" Hospital, University of Erlangen, Fuerth, Germany \\ 4. Department of Respiratory Diseases, Changhai Hospital/First Affiliated Hospital of the Secondary Military Medical University, \\ Shanghai, China \\ 5. Department of Interventional Pneumology, Ruhrlandklinik, University Hospital Essen, University of Essen-Duisburg, Essen, Germany \\ 6. Division of Pulmonology, Department of Clinical Therapeutics, National and Kapodistrian University of Athens School of Medicine, Alexandra Hospital, \\ Athens, Greece. \\ 7. Department of Pharmacology \& Clinical Pharmacology, School of Medicine, Faculty of Health Sciences, Aristotle University of Thessaloniki, Thessaloniki, \\ Greece \\ 8. Second Pulmonary Clinic, "Sotiria“" Chest Diseases Hospital, Athens, Greece.
}

$\triangle$ Corresponding author: Paul Zarogoulidis, M.D, Ph. D. Pulmonary Department-Oncology Unit, “G. Papanikolaou” General Hospital, Aristotle University of Thessaloniki, Thessaloniki, Greece. Fax: 00302310992424; Mobile: 00306977271974; E-mail: pzarog@hotmail.com.

(c) Ivyspring International Publisher. This is an open access article distributed under the terms of the Creative Commons Attribution (CC BY-NC) license (https:// creativecommons.org/licenses/by-nc/4.0/). See http://ivyspring.com/terms for full terms and conditions.

Received: 2016.10.19; Accepted: 2016.11.17; Published: 2017.03.10

\begin{abstract}
Lung cancer is the leading cause of cancer death among cancer patients with a higher rate for man, but soon also for women. New targeted treatments are already being used with the current addition of immunotherapy. However, for many patients there are several adverse effects or issues that emerge during therapy and there are cases where we would like to have local treatment options such as; in the case of microwave ablation, radiofrequency laser, argon plasma and cryotherapy. Endobronchial ultrasound system (linear) could be used and it has been used for local drug delivery into thoracic lymph nodes and lung cancer tumors.
\end{abstract}

Key words: endobronchial ultrasound, lung cancer, local therapy

\section{Lung Cancer Diagnosis and Staging}

Currently there are no blood biomarkers for early lung cancer detection as we have for other malignancies such as; prostate, gastrointestinal or gynecological cancer. [1] Most patients refer to doctors only if they have hemoptysis and persistent cough. Chest x-ray and computed tomography are usually the diagnostic examinations that follow. We can choose afterwards based on the findings to use endoscopic procedures such as; fiberoptic bronchoscopy or endobronchial ultrasound (radial/linear) for biopsy or fine needle aspiration (FNA) or FNBiopsy (true cut) [2]. There are also several novel combined techniques such as; electromagnetic navigation, however; the choice depends on the equipment that exists in each center and the experience of the center in each procedure. [2-5] Staging follows afterwards and a treatment decision is made for the patient by the oncology council of each hospital. [6] The EBUS system could also be used to evaluate non-thrombotic endovascular lesions in pulmonary arteries based on a recent publication. [7]

\section{Lung Cancer Treatment Options}

Non-specific cytotoxic agents until the previous decade were considered the tip of the arrow as first 
line treatment. [8] Unfortunately these drugs have and still have severe adverse effects for some patients. $[9,10]$ Due to the revolution in pharmacogenomics tyrosine kinase inhibitors are currently used for adenocarcinoma when we have epidermal growth factor positive mutation (EGFR) or anaplastic lymphoma kinase positive (ALK). [11-13] [14] Based on these gene mutations a whole new category of drugs was designed and is administered orally as "targeted" treatment the tyrosine kinase inhibitors. These drugs have also adverse effects mostly skin rash, gastrointestinal disorders and in some rare occasions diffuse lung disease. [15] [16] They are more efficient for this group of patients that can receive these agents. However; it has been observed that several patients receiving these agents present disease relapse or disease progression during treatment. This event can be observed immediately after initiation of the therapy (during the first month) or after several months of administration. [17] Therefore re-biopsy in the primary site or metastatic site is necessary in order to verify the novel mutation and administer the new tki. [17] In the case of relapse in a patient being alk positive, then ceritinib is administered. [18]

\section{Local Therapy for lung cancer}

There are clinical situations where a patient cannot receive intravenous chemotherapy or cannot receive oral treatment (TKIs). Currently debulking with argon plasma (APC), laser, mechanical debulking, radiotherapy or ablation (microwave/ radiofrequency) are used as an alternative treatment. [19-21] Several drug formulations have been used as intratumoral treatment either alone or in combination with other local methods such as; ablation or cryotherapy debulking. [22-24] Different success rates have been recorded depended on the tumor model and combination treatments.

\section{Endobronchial Ultrasound (EBUS) as a Tool for Local Treatment}

Administering locally drugs into tumors or lymph nodes has been previously presented by several groups.[4, 22-24] The endobronchial ultrasound system administered successfully to the target tissue the formulation.[22] The major issue that has to be discussed before any kind of application is the dosage of the formulation which should be based on the tissue volume, drug and matrix of the designated tissue.[22, 25] The major issue is to create a molecule that can efficiently penetrate the tumor tissue indifferent of its microenvironment, and with a smaller drug concentration to have a higher apoptosis rate. If these parameters are carefully combined then the drug formulation will be distributed homogenously within the tumor and the treatment will be effective. [26, 27] Figure 1.

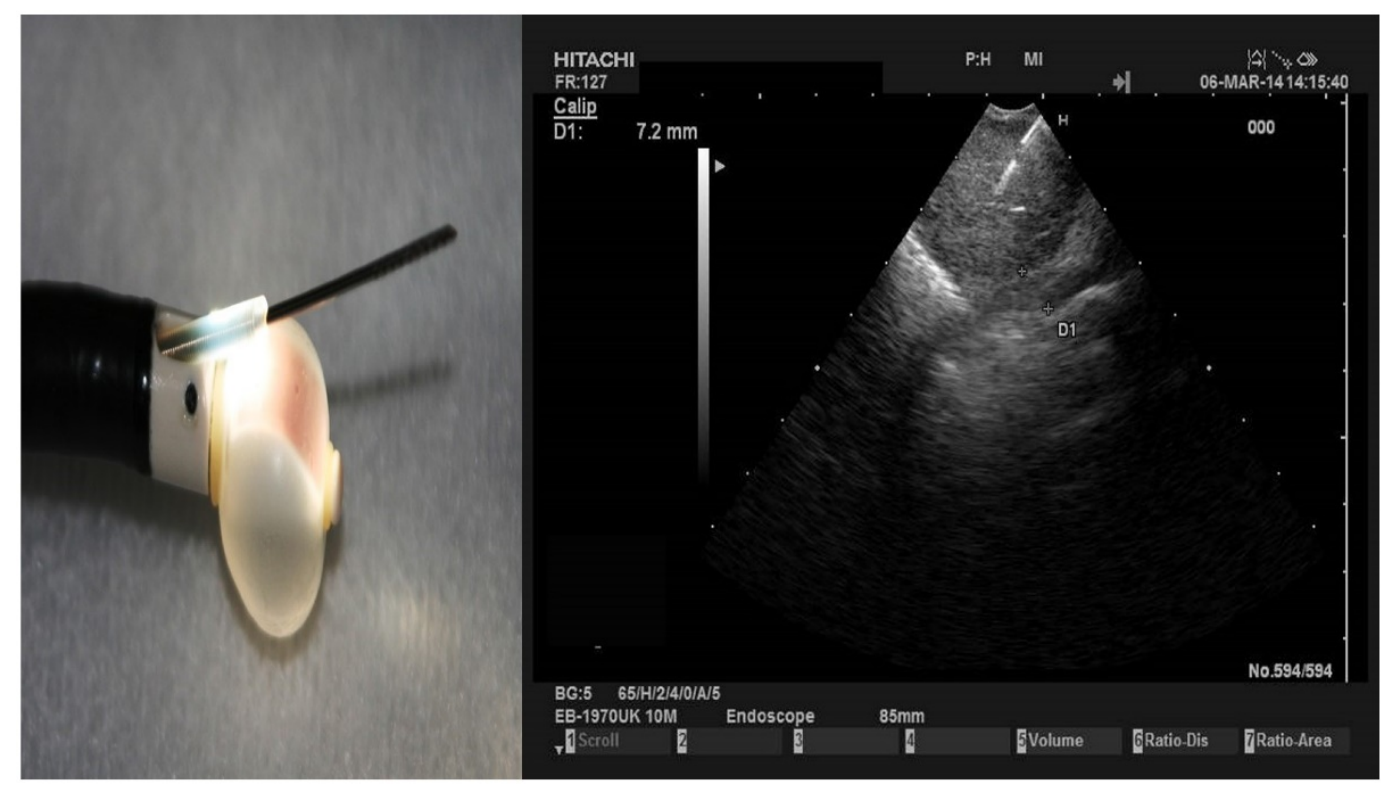

Figure 1. Left figure demonstrates the EBUS tip with a needle outside the protective seethe and the balloon dilated with water. The right figure demonstrates a lymph node punctured with the EBUS needle 22G. 


\section{Future Perspective}

Local treatment administration has certain advantages such as; low adverse effects in contrast to the intravenous chemotherapy administration. $[22,28$, 29] Several new drug formulations have been used and are necessary to overcome distribution issues within the tumor volume. [30] [31, 32] Direct intratumoral administration has the advantage that a lower dosage is used and several other systems such the lung parenchyma is bypassed. (Figure 2,3.) However; in several occasions, more than one target lesion exists and in several occasions a longer period of time is necessary for the application of the drug with the EBUS. In a case where severe respiratory distress exists this would be a severe obstacle to overcome. Therefore novel methods of airway respiration are used for such cases for patients with severe chronic obstructive pulmonary disease or respiratory distress. [33] Moreover; local ablation catheters through endoscopes could be a future alternative as local treatment either microwave or radiofrequency.

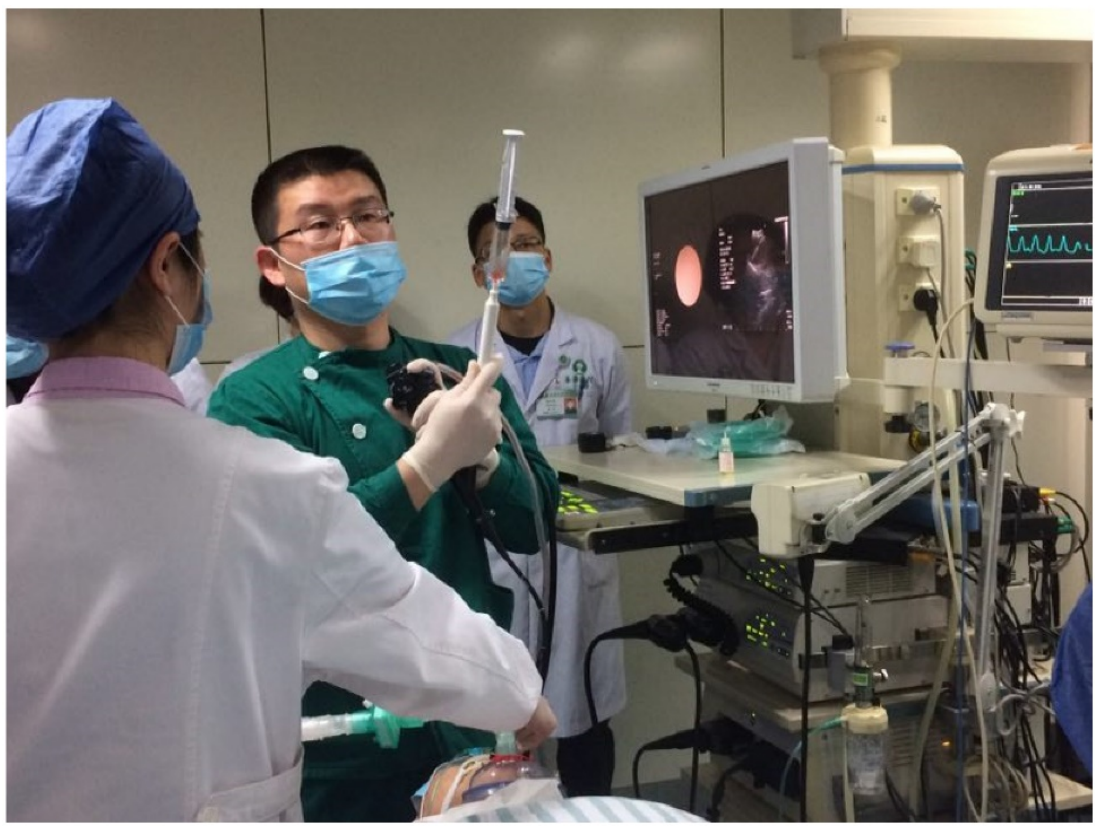

Figure 2. Dr. Haidong Huang performing EBUS in the Department of Respiratory Diseases, Changhai Hospital/First Affiliated Hospital of the Secondary Military Medical University, Shanghai, China

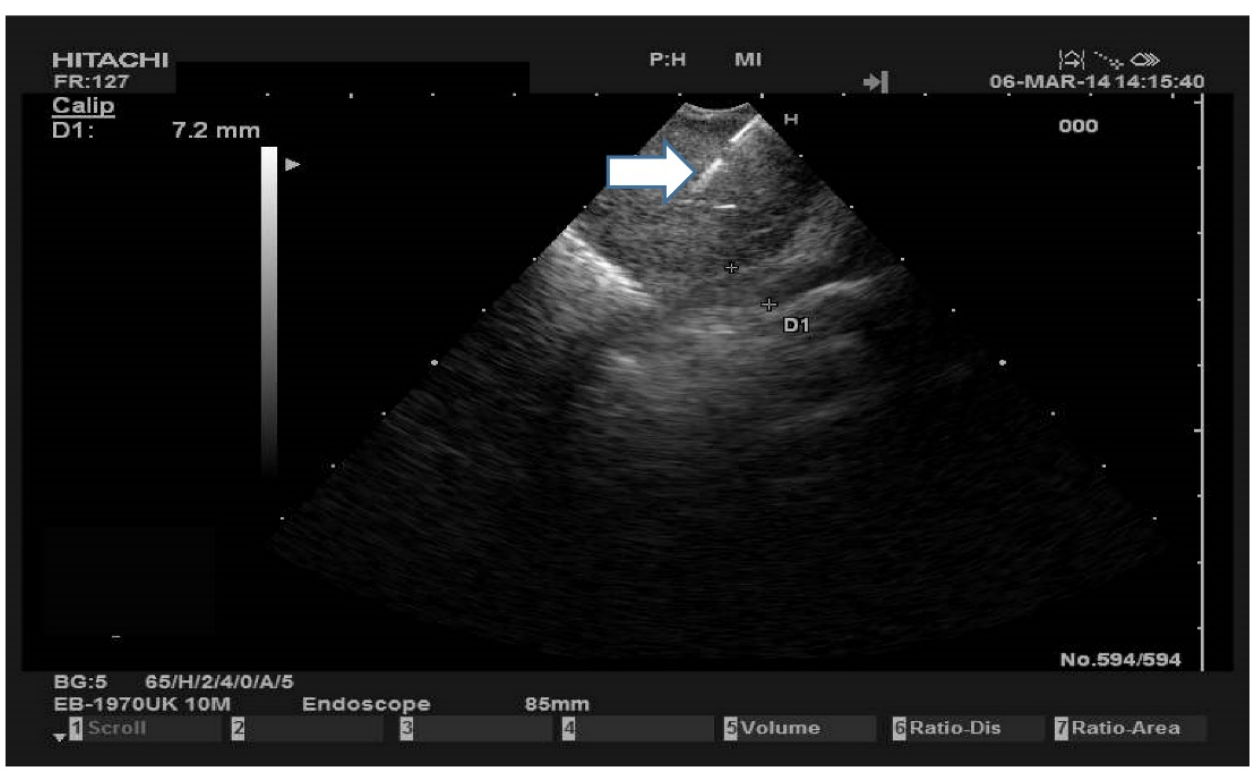

Figure 3. White arrow indicates the needle inside a lymph node 


\section{Conclusion}

After going through current studies, we could recommend local drug application in selected patients where intravenous or oral therapy cannot be administered due to performance status. The endobronchial ultrasound system has been used for several years and the safety of the equipment has been established. If the respiratory status or hematological status of the patient allows this method then it could be considered as an alternative treatment for a certain group of patients.

\section{Competing Interests}

The authors have declared that no competing interest exists.

\section{References}

1. Yuan J. Circulating protein and antibody biomarker for personalized cancer immunotherapy. Journal for immunotherapy of cancer. 2016; 4 : 46. doi:10.1186/s40425-016-0150-0.

2. Herth FJ, Eberhardt R, Schuhmann M. Bronchoscopy in lung cancer: navigational modalities and their clinical use. Expert review of respiratory medicine. 2016; 10: 901-6. doi:10.1080/17476348.2016.1191354.

3. Oezkan F, Khan A, Zarogoulidis P, Hohenforst-Schmidt W, Theegarten D, Yasufuku K, et al. Efficient utilization of EBUS-TBNA samples for both diagnosis and molecular analyses. OncoTargets and therapy. 2014; 7: 2061-5. doi:10.2147/OTT.S72974.

4. Hohenforst-Schmidt W, Zarogoulidis P, Vogl T, Turner JF, Browning R, Linsmeier B, et al. Cone Beam Computertomography (CBCT) in Interventional Chest Medicine - High Feasibility for Endobronchial Realtime Navigation. Journal of Cancer. 2014; 5: 231-41. doi:10.7150/jca.8834.

5. Ozgul G, Cetinkaya E, Ozgul MA, Abul Y, Gencoglu A, Kamiloglu E, et al. Efficacy and safety of electromagnetic navigation bronchoscopy with or without radial endobronchial ultrasound for peripheral lung lesions. Endoscopic ultrasound. 2016; 5: 189-95. doi:10.4103/2303-9027.183979.

6. Vilmann $\mathrm{P}$, Clementsen PF, Colella S, Siemsen M, De Leyn P, Dumonceau JM, et al. Combined endobronchial and oesophageal endosonography for the diagnosis and staging of lung cancer. European Society of Gastrointestinal Endoscopy (ESGE) Guideline, in cooperation with the European Respiratory Society (ERS) and the European Society of Thoracic Surgeons (ESTS). The European respiratory journal. 2015; 46: 40-60. doi:10.1183/09031936.00064515.

7. Al-Saffar F, Ibrahim S, Seeram V, Bajwa AA, Shujaat A. Use of endobronchial ultrasound to evaluate nonthrombotic endovascular lesions in pulmonary arteries: a systematic review. Journal of bronchology \& interventional pulmonology. 2015; 22: 28-32. doi:10.1097/LBR.0000000000000133.

8. Zarogoulidis K, Zarogoulidis P, Darwiche K, Boutsikou E, Machairiotis $\mathrm{N}$, Tsakiridis K, et al. Treatment of non-small cell lung cancer (NSCLC). Journal of thoracic disease. 2013; 5 Suppl 4: S389-96. doi:10.3978/j.issn.2072-1439.2013.07.10.

9. Yamaguchi Y, Tada Y, Takaya S, Iwamoto A, Yamashiro Y, Shibata S, et al. [A Case of Drug-Induced Lung Injury Associated with Paclitaxel plus Bevacizumab Therapy]. Gan to kagaku ryoho Cancer \& chemotherapy. 2016; 43: 781-4.

10. Mori A, Hirose T, Tamura A, Kusaka K, Matsui H, Ohta K. [Evaluation of the Efficacy and Safety of Platinum Doublet Re-Challenge Chemotherapy in Patients with Recurrent Advanced Non-Small Cell Lung Cancer]. Gan to kagaku ryoho Cancer \& chemotherapy. 2016; 43: 723-6.

11. Hohenforst-Schmidt $\mathrm{W}$, Zarogoulidis P, Steinheimer M, Benhassen N, Tsiouda T, Baka S, et al. Tyrosine Kinase Inhibitors for the Elderly. Journal of Cancer. 2016; 7: 687-93. doi:10.7150/jca.14819.

12. Papadopoulou E, Tsoulos N, Tsirigoti A, Apessos A, Agiannitopoulos K, Metaxa-Mariatou V, et al. Determination of EGFR and KRAS mutational status in Greek non-small-cell lung cancer patients. Oncology letters. 2015; 10: 2176-84. doi:10.3892/ol.2015.3600.

13. Milovancev A, Stojsic V, Zaric B, Kovacevic T, Sarcev T, Perin B, et al. EGFR-TKIs in adjuvant treatment of lung cancer: to give or not to give? OncoTargets and therapy. 2015; 8: 2915-21. doi:10.2147/OTT.S91627.

14. Lampaki S, Lazaridis G, Zarogoulidis K, Kioumis I, Papaiwannou A, Tsirgogianni K, et al. Defining the role of tyrosine kinase inhibitors in early stage non-small cell lung cancer. Journal of Cancer. 2015; 6: 568-74. doi:10.7150/jca.11893.

15. Shah RR. Tyrosine Kinase Inhibitor-Induced Interstitial Lung Disease: Clinical Features, Diagnostic Challenges, and Therapeutic Dilemmas. Drug safety. 2016. doi:10.1007/s40264-016-0450-9.

16. Zhao J, Zhang $\mathrm{K}$, Zhang L, Wang H. [Clinical Efficacy of Crizotinib in Advanced ALK Positive Non-small Cell Lung Cancer]. Zhongguo fei ai $\mathrm{za}$ zhi $=$ Chinese journal of lung cancer. 2015; 18: 616-20. doi:10.3779/j.issn.1009-3419.2015.10.03.

17. Ku BM, Bae YH, Koh J, Sun JM, Lee SH, Ahn JS, et al. AZD9291 overcomes T790 M-mediated resistance through degradation of EGFR(L858R/T790M) in non-small cell lung cancer cells. Investigational new drugs. 2016; 34: 407-15. doi:10.1007/s10637-016-0350-y.

18. Liu G, Zhang J, Zhou ZY, Li J, Cai X, Signorovitch J. Association between time to progression and subsequent survival in ceritinib-treated patients with advanced ALK-positive non-small cell lung cancer. Current medical research and opinion. 2016: 1-29. doi:10.1080/03007995.2016.1220934.

19. Sachdeva A, Pickering EM, Lee HJ. From electrocautery, balloon dilatation, neodymium-doped:yttrium-aluminum-garnet (Nd:YAG) laser to argon plasma coagulation and cryotherapy. Journal of thoracic disease. 2015; 7: S363-79. doi:10.3978/j.issn.2072-1439.2015.12.12.

20. Crombe A, Buy X, Godbert Y, Alberti N, Kind M, Bonichon F, et al. 23 Lung Metastases Treated by Radiofrequency Ablation Over 10 Years in a Single Patient: Successful Oncological Outcome of a Metastatic Cancer Without Altered Respiratory Function. Cardiovascular and interventional radiology. 2016. doi:10.1007/s00270-016-1445-8.

21. Hohenforst-Schmidt W, Zarogoulidis P, Pitsiou G, Linsmeier B, Tsavlis D, Kioumis I, et al. Drug Eluting Stents for Malignant Airway Obstruction: A Critical Review of the Literature. Journal of Cancer. 2016; 7: 377-90. doi:10.7150/jca.13611

22. Hohenforst-Schmidt W, Zarogoulidis P, Darwiche K, Vogl T, Goldberg $\mathrm{EP}$, Huang $\mathrm{H}$, et al. Intratumoral chemotherapy for lung cancer: re-challenge current targeted therapies. Drug design, development and therapy. 2013; 7: 571-83. doi:10.2147/DDDT.S46393.

23. Hohenforst-Schmidt W, Zarogoulidis P, Stopek J, Kosmidis E, Vogl T, Linsmeier B, et al. Enhancement of Intratumoral Chemotherapy with Cisplatin with or without Microwave Ablation and Lipiodol. Future Concept for Local Treatment in Lung Cancer. Journal of Cancer. 2015; 6: 218-26. doi:10.7150/jca.10970.

24. Baliaka A, Zarogoulidis P, Domvri K, Hohenforst-Schmidt W, Sakkas A, Huang $\mathrm{H}$, et al. Intratumoral gene therapy versus intravenous gene therapy for distant metastasis control with 2-diethylaminoethyl-dextran methyl methacrylate copolymer non-viral vector-p53. Gene therapy. 2014; 21: 158-67. doi:10.1038/gt.2013.68

25. Hu Q, Kang $\mathrm{T}$, Feng J, Zhu Q, Jiang $\mathrm{T}$, Yao J, et al. Tumor Microenvironment and Angiogenic Blood Vessels Dual-Targeting for Enhanced Anti-Glioma Therapy. ACS applied materials \& interfaces. 2016. doi:10.1021/acsami.6b08239.

26. Mehta HJ, Begnaud A, Penley AM, Wynne J, Malhotra P, Fernandez-Bussy S, et al. Treatment of isolated mediastinal and hilar recurrence of lung cancer with bronchoscopic endobronchial ultrasound guided intratumoral injection of chemotherapy with cisplatin. Lung cancer. 2015; 90: 542-7. doi:10.1016/j.lungcan.2015.10.009.

27. Khan F, Anker CJ, Garrison G, Kinsey CM. Endobronchial ultrasound-guided transbronchial needle injection for local control of recurrent non-small cell lung cancer. Annals of the American Thoracic Society. 2015; 12: 101-4. doi:10.1513/AnnalsATS.201408-358BC.

28. Darwiche $\mathrm{K}$, Zarogoulidis $\mathrm{P}$, Karamanos NK, Domvri K, Chatzaki E, Constantinidis $\mathrm{TC}$, et al. Efficacy versus safety concerns for aerosol chemotherapy in non-small-cell lung cancer: a future dilemma for micro-oncology. Future oncology. 2013; 9. 505-25. doi:10.2217/fon.12.205.

29. Zarogoulidis P, Eleftheriadou E, Sapardanis I, Zarogoulidou V, Lithoxopoulou H, Kontakiotis T, et al. Feasibility and effectiveness of inhaled carboplatin in NSCLC patients. Investigational new drugs. 2012; 30: 1628-40. doi:10.1007/s10637-011-9714-5.

30. Wang Y, Rong J, Zhang J, Liu Y, Meng X, Guo H, et al. Morphology, in vivo distribution and antitumor activity of bexarotene nanocrystals in 
lung cancer. Drug development and industrial pharmacy. 2016: 1-10. doi:10.1080/03639045.2016.1225752.

31. Li H, Zhang K, Pi F, Guo S, Shlyakhtenko L, Chiu W, et al. Controllable Self-Assembly of RNA Tetrahedrons with Precise Shape and Size for Cancer Targeting. Advanced materials. 2016. doi:10.1002/adma.201601976.

32. Zarogoulidis P, Darwiche K, Hohenforst-Schmidt W, Huang H, Li Q, Freitag L, et al. Inhaled gene therapy in lung cancer: proof-of-concept for nano-oncology and nanobiotechnology in the management of lung cancer. Future oncology. 2013; 9: 1171-94. doi:10.2217/fon.13.67.

33. Hohenforst-Schmidt W, Linsmeier B, Zarogoulidis P, Freitag L, Darwiche K, Browning R, et al. Transtracheal single-point stent fixation in posttracheotomy tracheomalacia under cone-beam computer tomography guidance by transmural suturing with the Berci needle - a perspective on a new tool to avoid stent migration of Dumon stents. Therapeutics and clinical risk management. 2015; 11: 837-50. doi:10.2147/TCRM.S83230. 